\title{
The Asthma Control Test (ACT) as an alternative tool to Global Initiative for Asthma (GINA) guideline criteria for assessing asthma control in Vietnamese outpatients
}

\author{
*Vinh Nhu Nguyen", Niels Chavannes ${ }^{b}$, Lan Thi Tuyet Le ${ }^{c}$, David Price \\ a Family Medicine Department, University of Medicine and Pharmacy, Ho Chi Minh City, Vietnam \\ b Department of Public Health and Primary Care, Leiden University Medical Center, Leiden, The Netherlands \\ Physiology Department, University of Medicine and Pharmacy, Ho Chi Minh City, Vietnam \\ ${ }^{d}$ Centre of Academic Primary Care, University of Aberdeen, Aberdeen, UK
}

Received 12th June 2011; resubmitted 19th August 2011; revised 7th September 2011; accepted 9th September 2011; online 26th October 2011

\begin{abstract}
Aims: To determine the reliability and validity of the Asthma Control Test (ACT) to detect Global Initiative for Asthma (GINA)-defined uncontrolled or partly controlled asthma, and to determine the agreement between ACT and GINA in classifying asthma control among Vietnamese patients.

Methods: A cross-sectional study was performed in 323 of 360 invited outpatients with asthma in Ho Chi Minh City to compare the ACT and GINA classification for asthma control.

Results: Internal consistency of the ACT (Cronbach's alpha) was 0.83 . The kappa coefficient of 0.55 , based on the ternary split, represents moderate agreement between the two rating systems with a correctly classified rate of $75 \%$. The area under the receiver operating characteristics curve for the ACT score predicting GINA control was 0.85. To detect GINA-defined 'not controlled asthma', the ACT had a sensitivity of $70 \%$, specificity of $93 \%$, and a positive predictive value of $89 \%$, with a cut-off point of 19 . The validity of the ACT with regard to agreement with the GINA classification was consistent across both sexes, but less so in adolescents or younger adults. The ACT score was significantly correlated with the percentage predicted forced expiratory volume in 1 second $(r=0.35, p<0.001)$ and percentage predicted peak expiratory flow $(r=0.26, p<0.001)$.

Conclusions: The Vietnamese ACT is useful for identifying outpatients with GINA-defined uncontrolled or partly controlled asthma.

(C) 2012 Primary Care Respiratory Society UK. All rights reserved.

VN Nguyen et al. Prim Care Respir J 2012; 21(1): 85-89

http://dx.doi.org/10.4104/pcrj.2011.00093
\end{abstract}

Keywords asthma control, asthma control test, GINA guideline, Vietnam, ACT

The full version of this paper, with online appendices,

is available online at www.thepcrj.org

\section{Introduction}

The prevalence of asthma in Vietnam is estimated to be $5 \%$ in adults. ${ }^{1}$ Although asthma is not curable it is treatable, and the best way to reduce the burden of disease is to control it. Current Global Initiative for Asthma (GINA) guidelines emphasise the need to evaluate asthma control to guide asthma management decisions. ${ }^{2}$ Guideline-defined asthma control can be achieved and maintained for the majority of patients in controlled trial settings. ${ }^{3-5}$ In Vietnam, the GINA guidelines were recently used as the main reference source for the national asthma guidelines. ${ }^{1}$ A recent study suggested that the level of asthma control in Vietnam is poorer than expected, with less than $1 \%$ of patients studied meeting the definition of asthma control. ${ }^{6}$ Apart from the lack of preventive medications, limited access to asthma control assessment is another factor responsible for this poor level of asthma control. It is difficult to follow GINA criteria to evaluate asthma control because of the lack of access to lung function assessment. A simple, applicable, and accessible but validated tool to assess asthma control is therefore urgently

\footnotetext{
* Corresponding author: Dr Vinh Nhu Nguyen, Family Medicine Department, University of Medicine and Pharmacy, 217 Hong Bang St, District 5, Ho Chi Minh City 70000, Vietnam. Tel: 84-3-8558411/84-3-9509762 Fax: 84-8-38552304 E-mail: bsvinhnguyen@yahoo.com.
} 
needed for patients with asthma in Vietnam. The Asthma Control Test (ACT) questionnaire - a simple, self-administered, and rapidly completed assessment tool - might be appropriate to meet this demand. ${ }^{7-9}$ The ACT has the added advantages that it does not require lung function assessments and can be applied at all levels of healthcare. ${ }^{7,10}$ However, this tool has not been validated as a reliable predictor of GINA-defined asthma control in Vietnam. A study was therefore undertaken to validate the Vietnamese version of the ACT.

\section{Methods}

This was a prospective study recruiting ambulatory patients aged $\geq 12$ years with asthma at the University Medical Centre, Ho Chi Minh City, Vietnam between January 2008 and January 2009. The objective was to determine the reliability and validity of the ACT as a means of detecting GINA-defined uncontrolled and partly controlled asthma (together labelled 'not-controlled asthma' according to GINA). The study also set out to determine the reliability and validity of the agreement between ACT and GINA in classifying asthma control, as well as to determine the consistency across age, gender, and asthma severity subgroups.

Patients who satisfied the inclusion criteria ( $\geq 12$ years old, asthma diagnosed according to GINA in the past 6 months, literate in Vietnamese, and able to perform spirometry) were included in the study. Subjects were excluded if they had any of the following exclusion criteria: hospitalised for asthma or had an acute upper or lower respiratory tract infection within 4 weeks prior to study; had a known respiratory disorder other than asthma and/or systemic/thoracic abnormalities that influence normal lung function; or had smoked $\geq 10$ pack-years. All eligible patients had to provide informed consent before being entered into the study.

The questionnaire used was the ACT Vietnamese version for adults, downloaded from www.asthmacontroltest.com with user approval obtained from the authorised owner.

With a presumption based on the literature that the ACT can detect GINA-defined 'not-controlled asthma' with a sensitivity of $70 \%$ and a specificity of $75 \%, 7,8$ the calculated sample size was 323 subjects.

Eligible patients answered and submitted the ACT questionnaire to the investigators before physician assessment. Patients then performed spirometry tests followed by interviews with a pulmonologist who evaluated their asthma control and provided treatment modifications as required.

A cognitive debriefing was performed with 20 patients before conducting an official debriefing. The modified questionnaire was re-tested with 10 other asthmatic patients. The final version of the questionnaire was then used for this research.

\section{Data analysis}

SPSS Version 16.0 software was used to analyse the data and a $p$ value of $<0.05$ was considered statistically significant. Cronbach's alpha was used to determine the internal reliability of the five items of the questionnaire.
The validity of the ACT as a means of detecting GINAdefined 'not-controlled asthma' using the GINA binary split criterion as the gold standard ('not-controlled' being combined uncontrolled and partly controlled asthma versus controlled asthma) was determined by sensitivity, specificity, positive and negative predictive values (PPV and NPV), likelihood ratios (LR), the correctly classified rate and area under the ROC curve (AUC). In the ternary split of GINA-defined asthma control, the agreement between GINA rating (uncontrolled, partly controlled and controlled asthma) and ACT rating (ACT score <15, 15-19 and 20-25) in the classification of asthma control was determined using the kappa coefficient of agreement and correctly classified rates.

Subgroup analyses were undertaken based on asthma severity, gender, and age to explore the consistency of the validity of the ACT and its agreement with GINA across the subgroups.

Spearman's coefficient between the ACT and three levels of treatment modifications, as well as ANOVA testing to assess the differences in mean ACT scores among these levels, were applied.

The relationship between ACT and the percentage of forced expiratory volume in 1 second $\left(\% \mathrm{FEV}_{1}\right)$ compared with the predicted value, and between ACT and the percentage of peak expiratory flow (\%PEF) compared with the predicted value, was determined by Pearson correlation coefficients ( $r$ ).

\section{Results}

\section{Revision of the questionnaire}

The cognitive debriefing showed that most patients understood four of the five questions. However, the fourth question caused confusion as it asked about rescue medication usage but some patients answered about preventive medication. The question was then revised by rewording as 'rescue medication' and giving a brief explanation of what these medications actually are, citing examples such as salbutamol and Ventolin which are known and commonly used in Vietnam. The revised version questionnaire then underwent further cognitive debriefing, resulting in no residual confusion.

\section{Characteristics of study patients}

A total of 360 patients were invited to participate in the study; $323(90 \%)$ of mean age 36 years (range 12-80) agreed to participate. Females comprised $57 \%$ of the participants with a mean percentage predicted $\mathrm{FEV}_{1}$ and PEF of $86 \%$ and $88.6 \%$, respectively, and a mean ACT score of 20.5. Other characteristics are described in Table 1, in which GINA stage 3 is prominent $(28 \%)$, but in general the patients were equally distributed among the four stages. Most of the patients were using preventive medication; the majority had controlled asthma according to both GINA and ACT criteria and were continued on the same treatment after their visit.

\section{Reliability and empirical validity of the ACT}

Cronbach's alpha was 0.83 , indicating a high consistency among the answers to the five questions of the ACT questionnaire.

The cut-off point for the ACT in detecting GINA 'not- 


\begin{tabular}{|c|c|c|}
\hline & No & $\%$ \\
\hline \multicolumn{3}{|l|}{ Asthma severity according GINA } \\
\hline Stage 1 & 71 & 22 \\
\hline Stage 2 & 82 & 25 \\
\hline Stage 3 & 90 & 28 \\
\hline Stage 4 & 80 & 25 \\
\hline \multicolumn{3}{|l|}{ Preventive medication use before visit } \\
\hline No preventive drugs & 14 & 4.3 \\
\hline Inhaled corticosteroid (ICS) & 65 & 20.1 \\
\hline Combination of ICS and long-acting $\beta_{2}$-agonist & 244 & 75.5 \\
\hline \multicolumn{3}{|l|}{ Asthma control } \\
\hline \multicolumn{3}{|l|}{ GINA classification } \\
\hline Uncontrolled & 48 & 14.9 \\
\hline Partly controlled & 97 & 30 \\
\hline Controlled & 178 & 55.1 \\
\hline \multicolumn{3}{|l|}{ ACT classification } \\
\hline Uncontrolled & 31 & 9.6 \\
\hline Partly controlled & 84 & 26 \\
\hline Controlled & 208 & 64.4 \\
\hline \multicolumn{3}{|l|}{ Treatment modification } \\
\hline Maintain current treatment & 133 & 41.2 \\
\hline Step up & 72 & 22.3 \\
\hline Step down & 118 & 36.5 \\
\hline
\end{tabular}

controlled asthma' was 19, which yielded the largest AUC of 0.85 with a sensitivity of $70 \%$, specificity of $73 \%$, PPV of $89 \%$, NPV of $79 \%$, positive LR of 9.6, negative LR of 0.3 , and a correctly classified rate of $83 \%$. These characteristics indicate a good screening tool. The consistency of these findings was maintained across subgroups of patients based on gender, age, and asthma severity (see Appendix 1 available online at www.thepcrj.org).

Agreement between ACT and GINA in dassifying three levels of asthma control

The kappa value was 0.55 (Table 2), indicating a moderate level of agreement beyond chance between the two rating systems $(\hat{l}=0.4-0.6) .^{11,12}$ Both rating systems correctly classified $75 \%$ at three levels of asthma control.

In subgroup analyses (see Appendix 2 available online at www.thepcrj.org), the kappa coefficient and correctly classified rates were worse in patients with stage 4 asthma than in those with other stages. These two parameters were, however, similar in patients with mild asthma (stages 1 and 2) and in those with moderate to severe asthma (stages 3 and 4), and in females compared with males. On the other hand, the kappa coefficient indicated only fair agreement in adolescents $(0.2<\kappa=0.39<0.4)$ with a correctly classified rate of $69 \%$, which is worse than in adults who had a kappa of 0.58 and a correctly classified rate of $76 \%$.

Responsiveness of the ACT to specialist treatment modification

The ACT scores for groups receiving different asthma treatment decisions after medical assessment are shown in Table 3. The mean ACT score was similar for those in whom treatment was
Table 2. Agreement between GINA classification and ACT classification of asthma control

\begin{tabular}{l|l|l|l|l}
\multirow{2}{*}{ ACT } & \multicolumn{3}{|l|}{ GINA-defined control } & Total \\
\cline { 2 - 4 } & $\begin{array}{l}\text { Uncontrolled } \\
\mathrm{n}(\%)\end{array}$ & $\begin{array}{l}\text { Partly } \\
\text { controlled } \\
\mathrm{n}(\%)\end{array}$ & $\begin{array}{l}\text { Controlled } \\
\mathrm{n}(\%)\end{array}$ & \\
\hline $\begin{array}{l}\text { ACT }<15 \\
\text { (uncontrolled) }\end{array}$ & $27(8.4)$ & $4(1.2)$ & $0(0)$ & $31(9.6)$ \\
\hline $\begin{array}{l}\text { ACT 15-19 } \\
\text { (partly controlled) }\end{array}$ & $21(6.5)$ & $50(15.5)$ & $13(4.0)$ & $84(26.0)$ \\
\hline $\begin{array}{l}\text { ACT } \geq 20 \\
\text { (controlled) }\end{array}$ & $0(0)$ & $4313.3)$ & $165(51.1)$ & $208(64.4)$ \\
\hline Total $\mathrm{n}(\%)$ & $48(14.9)$ & $97(30.0)$ & $178(55.1)$ & $323(100)$ \\
\hline
\end{tabular}

Kappa $=0.55, p<0.001$, correctly classified rate $=75 \%$

$\mathrm{ACT}=$ Asthma Control Test; GINA=Global Initiative for Asthma

Table 3. Difference in mean Asthma Control Test (ACT) score across three categories of treatment modification

\begin{tabular}{l|l|l|l|l} 
& \multicolumn{3}{|l|}{ Treatment modification } & $\begin{array}{l}\text { Total } \\
(n=323)\end{array}$ \\
\cline { 2 - 4 } & $\begin{array}{l}\text { Stepping } \\
\text { down } \\
(n=118)\end{array}$ & $\begin{array}{l}\text { Maintaining } \\
(n=133)\end{array}$ & $\begin{array}{l}\text { Stepping } \\
\text { up } \\
(n=72)\end{array}$ & \\
\hline Mean ACT score & 21.6 & 21.6 & 16.6 & 20.5 \\
\hline
\end{tabular}

$p<0.001$ (ANOVA test)

either maintained or stepped down $(p=0.9)$ but much lower in those in whom treatment was stepped up. There was a significant correlation between the ACT score and asthma treatment modification (Spearman's $r=-0.36, p<0.001$ ).

Relationship between ACT score and \% $\mathrm{FEV}_{1}$ and \% PEF The Pearson coefficient between the ACT score and $\% \mathrm{FEV}_{1}$ was $0.35(p<0.001)$ and between the ACT score and \%PEF it was $0.26(p<0.001)$.

\section{Discussion}

Achieving and maintaining asthma control are fundamental elements of asthma management. ${ }^{2}$ Practical tools are needed to assess asthma control in asthma management. Most tools used to evaluate asthma control consider airflow obstruction as a criterion. However, this is often very difficult to perform in developing countries such as Vietnam because spirometers and peak flow meters are not readily available. A tool is required that measures the multidimensional nature of asthma control and that is easy and quick to administer and interpret in order to facilitate the assessment of asthma control in clinical practice. The ACT has proved to be a valid tool for this purpose in other settings. ${ }^{7-9}$

\section{Main findings, and interpretation in relation to} previously published work

This is the first evaluation of the ACT undertaken in Vietnam. It was found to be able to predict GINA-defined 'not-controlled asthma' (positive LR 9.6, PPV 89\%) with a sensitivity of 70\% and a specificity of $93 \%$. The sensitivity is similar to studies from 
America $(69-71 \%)^{7,9}$ and Hong Kong $(70.5 \%){ }^{13}$ but lower than figures reported in China $(80 \%)^{14}$ and Korea $\left.(85 \%)\right)^{15}$ The specificity is similar to a study from Korea $(93 \%),{ }^{15}$ and reached a higher level than in some other countries. ${ }^{7,9,13,14,16}$ With a cut-off point of $\leq 19$, the ACT correctly predicted GINA-defined 'notcontrolled asthma' in $89 \%$ of cases while an ACT score of $\geq 20$ predicted GINA-defined controlled asthma in $79 \%$ of cases. The area under the ROC curve (AUC) was acceptable at 0.85 (95\% $\mathrm{Cl} 0.80$ to 0.88 ) and of similar magnitude to previous findings for the ACT. ${ }^{7.14,17-20}$ The ACT has been shown to be a reliable tool by previous authors, ${ }^{7,8,14-17,21,22}$ and this is confirmed by this study in a Vietnamese outpatient setting in which Cronbach's alpha reached 0.83 , indicating a high consistency among the answers to the five questions.

Most patients in this study population were using preventive medications (Table 1). These numbers are much higher than those in other studies (6-13.6\%), ${ }^{23,24}$ including a Vietnamese subgroup in an international study. ${ }^{23}$ This may explain why the number of patients with severe asthma in this study is higher than in some other studies, ${ }^{23,25-28}$ while the rate of patients with controlled asthma in this study is also higher than that in other studies. ${ }^{23,26,28}$ This result supports the concept that severity may not be an important index in asthma management. ${ }^{2}$ It is clear that $53 \%$ of patients in this study had moderate to severe asthma, but their asthma control is good because of their use of preventer therapy. On the other hand, the proportion of patients with moderate to severe asthma in some other studies is low and the rate of asthma control is also quite low, ${ }_{1}^{23,25,27,28}$ which may be due to lack of appropriate therapy or a poor response to such therapy.

In this study a maximum ACT score of 25 indicates controlled asthma; $94.7 \%$ of those with an ACT score of 25 had controlled asthma, 5.3\% had partly controlled asthma and none had uncontrolled asthma according to the GINA definition. In addition, patients who responded with the maximum 5 points for the fifth question (indicating their asthma is completely controlled) can be relied upon in our study population. Seventythree patients in this study responded with 5 points for the fifth question, of whom $83.6 \%$ had controlled asthma, $16.4 \%$ had partly controlled asthma, and $0 \%$ had uncontrolled asthma according to the GINA definition. This suggests that, in patients who rated 5 points for the fifth ACT question or had an ACT total score of 25, none had GINA-defined uncontrolled asthma.

The kappa level of agreement between the two systems was 0.55 , representing moderate agreement between the two rating systems, ${ }^{11}$ while the correctly classified rate was $75 \%$. Another positive finding in this study was no extreme difference in classification of asthma control between the two rating systems: no patient had an ACT score of $\geq 20$ while having GINA-defined uncontrolled asthma and no patient with GINAdefined controlled asthma had an ACT score of <15 (Table 2).

The subgroup analyses (Appendices 1 and 2) showed that the value of the ACT in detecting GINA-defined 'not-controlled asthma' and the agreement between the ACT and GINA in classifying asthma control was similar in both sexes and groups of patients who had mild asthma (stages 1 and 2) to those who had moderate to severe asthma (stages 3 and 4). The correctly classified rate in assessing asthma control of the two rating systems (GINA and ACT) (both two-level and three-level classification) was worse in patients with stage 4 asthma (75\% and $69 \%$, respectively). The validity of the ACT in adolescents is worse than in adults with regard to all test parameters except specificity. The same was found when comparing the younger age group with the older age group. This may be because adolescents and younger adults pay less attention to their health, resulting in recall bias during the completion of the questionnaire. This was confirmed again by the kappa agreement coefficients and the correctly classified rates of adolescents and younger groups, which were poorer than those in older age groups.

Some studies state that the ACT is poorly correlated with $\mathrm{FEV}_{1}{ }^{17}$ or suggest that it correlates better with PEF than with $\mathrm{FEV}_{1}{ }^{29}$ but the present study found the opposite. The ACT total score was correlated with $\% \mathrm{FEV}_{1}(r=0.35, \mathrm{p}<0.001)$ and this correlation was better than the correlation between the ACT and \%PEF ( $r=0.26, p<0.001)$.

The mean ACT score of those who were stepped up (16.6) was significantly lower than the mean score of those who were stepped down (21.6) and those who were maintained on treatment (21.6) $(p<0.001$, Table 3$)$. This suggests that ACT can usefully predict patients who need increased treatment due to poor asthma control. This is important in clinical practice because these patients need to have their treatment reviewed as well as addressing risk factors for poor asthma control..$^{30} \mathrm{~A}$ study of 382 patients in Hong Kong found that the ACT could predict step-up of asthma therapy in $70.2 \%$ of consultations, ${ }^{13}$ suggesting that this tool could actually assist doctors' treatment decisions. Indeed, Ko et al. found that the ACT correlates better with treatment decisions made by asthma specialists than spirometry, PEF, or fractional exhaled nitric oxide measurements. ${ }^{13}$

\section{Limitations of the study}

This study has several limitations, including the possibility of patient selection bias as participants represent a convenience sample from a teaching hospital which may not be representative of the overall population of outpatients with asthma in Vietnam. Patients' recall of asthma symptoms may not be entirely accurate and we cannot rule out recall bias on the part of participating patients. Another limitation is choosing the GINA 2006 classification of asthma control as the gold standard assessment of asthma control. However, there is no real gold standard for measuring asthma control; even the GINA classifications are described as a 'working scheme based on current opinion which has not been validated'. ${ }^{2}$

In spite of these limitations, the study provides evidence that the Vietnamese ACT is a reliable tool to assess asthma control and, with a cut-off point of 19, it can predict GINA-defined 'not- 
controlled asthma' with a high PPV and a high positive LR. It appears to be a good tool to predict GINA-defined 'not-controlled asthma' and can predict the step-up decision of doctors.

\section{Conclusions}

The ACT is a reliable and simple tool that does not require spirometry measurements. This might be a significant asset in the management of outpatients with asthma in Vietnam. The questionnaire score correlates well with treatment modifications and lung function parameters (FEV 1 and PEF). The ACT is easily and quickly completed by patients and can serve as a useful tool in everyday practice to guide adjustments in asthma therapy.

\section{Handling editor Mike Thomas \\ Statistical review Gopal Netuveli}

Conflicts of interest The authors declare that they have no conflicts of interest in relation to this article

Contributorship VNN designed, conducted the study and wrote the paper. NC, LTTL and DP contributed in proposal and paper writing.

Funding The University of Medicine and Pharmacy, Hochiminh city, Vietnam.

\section{References}

1. Vietnamese asthma management guideline. Ministry of Health, 2009

2. Global Initiative for Asthma. Global strategy for asthma management and prevention. Revised 2006. http://www.ginaasthma.com (accessed 25 June 2007).

3. Bateman ED, Bousquet J, Braunstein GL. Is overall asthma control being achieved? A hypothesis-generating study. Eur Respir J 2001;17(4):589-95 http://dx.doi.org/10.1183/09031936.01.17405890

4. Bateman ED, Boushey HA, Bousquet J, et al. Can guideline-defined asthma control be achieved? The Gaining Optimal Asthma ControL study. Am J Respir Crit Care Med 2004;170(8):836-44. http://dx.doi.org/10.1164/rccm.200401-0330C

5. Thomas M, Kay S, Pike J, et al. The Asthma Control Test (ACT) as a predictor of asthma guidelines-specified control: analysis of a multinational cross-sectional survey. Prim Care Respir J 2009;18(1):41-9. http://dx.doi.org/10.4104/ pcrj.2009.00010

6. Lai CK, De Guia TS, Kim YY, et al. Asthma control in the Asia-Pacific region: the Asthma Insights and Reality in Asia-Pacific Study. J Allergy Clin Immunol 2003;111(2):263-8. http://dx.doi.org/10.1067/mai.2003.30

7. Nathan RA, Sorkness CA, Kosinski M, et al. Development of the asthma control test: a survey for assessing asthma control. J Allergy Clin Immunol 2004;113(1):59-65. http://dx.doi.org/10.1016/j.jaci.2003.09.008

8. Schatz M, Sorkness CA, Li JT, et al. Asthma Control Test: reliability, validity, and responsiveness in patients not previously followed by asthma specialists. J Allergy Clin Immunol 2006;117(3):549-56. http://dx.doi.org/10.1016/j.jaci.2006.01.011

9. Schatz M, Mosen DM, Kosinski M, et al. Validity of the Asthma Control Test completed at home. Am J Manag Care 2007;13(12):661-7.

10. Chhabra SK. Assessment of control in asthma: the new focus in management. Indian J Chest Dis Allied Sci 2008;50:109-16.

11. Landis JR, Koch GG. The measurement of observer agreement for categorical data. Biometrics 1977;33(1):159-74. http://dx.doi.org/10.2307/2529310

12. Swinscow TDV. Statistics at Square One. London: BMJ Publishing, 1997.

13. Ko FW, Leung TF, Hui DS, et al. Asthma Control Test correlates well with the treatment decisions made by asthma specialists. Respirology 2009;14(4):559-66. http://dx.doi.org/10.1111/j.1440-1843.2009.01514.x
14. Zhou X, Ding FM, Lin JT, et al. Validity of Asthma Control Test in Chinese patients. Chin Med J 2007;120(12):1037-41.

15. Kwon HS, Lee SH, Yang MS, et al. Correlation between the Korean version of Asthma Control Test and health-related quality of life in adult asthmatics. J Korean Med Sci 2008;23(4):621-7. http://dx.doi.org/10.3346/jkms.2008.23.4.621

16. Vega JM, Badia X, Badiola C, et al. Validation of the Spanish version of the Asthma Control Test (ACT). J Asthma 2007:44(10):867-72.

http://dx.doi.org/10.1080/02770900701752615

17. Laercio MV, Benevenuto G, Coelho RS, Vasconcelos AV, Osterne TE, Aguiar JC. Asthma Control Test (ACT) compared with spirometry in the assessment of patients with asthma, poster presentations. Chest 2006 http://meeting.chestpubs.org/cgi/content/abstract/130/4/160S-a

18. Price DB, Tinkelman DG, Nordyke RJ, Isonaka S, Halbert RJ. Scoring system and clinical application of COPD diagnostic questionnaires. Chest 2006;129(6):1531-9. http://dx.doi.org/10.1378/chest.129.6.1531

19. Wallenstein GV, Carranza-Rosenzweig J, Kosinski M, Blaisdell-Gross B, Gajria K, Jhingran P. A psychometric comparison of three patient-based measures of asthma control. Curr Med Res Opin 2007;23(2):369-77. http://dx.doi.org/10.1185/030079906X167426

20. Weintraub JM, Sparrow D, Weiss ST. Receiver operating characteristics curve analysis of cutaneous skin test reactions to predict hay fever and asthma symptoms in the Normative Aging Study. Allergy 2001;56(3):243-6. http://dx.doi.org/10.1034/j.1398-9995.2001.056003243.x

21. Atilla Uysal, Banu Altoparlak, Nazan Bayram and Sedat Altin. Asthma control test how? And where? http://www.ersnet.org/learning_resources_player/ abstract_print_08/files/294.pdf

22. Lababidi H, Hijaoui A, Zarzour M. Validation of the Arabic version of the asthma contro test. Ann Thorac Med 2008;3(2):44-7. http://dx.doi.org/10.4103/1817-1737.39635

23. Lai CKW, Kim Y-Y, Kuo S-H, Williams AE. Cost of asthma in the Asia-Pacific region. Eur Respir Rev 2006;15:98, 10-16. http://dx.doi.org/10.1183/09059180.06.00009802

24. Neffen K, Fritscher C, Cuevas Schacht F, et al. Asthma control in Latin America: the Asthma Insights and Reality in Latin America (AIRLA) survey. Rev Panam Salud Publica 2005;17(3):191-7. http://dx.doi.org/10.1590/S1020-49892005000300007

25. Boonsawat W, Charoenphan P, Kiatboonsri S, et al. Survey of asthma control in Thailand Respirology 2004;9(3):373-8. http://dx.doi.org/10.1111/j.1440-1843.2004.00584.x

26. Maria Monica R. Mendoza, Bernice Ong-Dela Cruz, Aileen V. Guzman-Banzon, Fernando G. Ayuyao and Teresita S. De Guia. Comparative Assessment of Asthma Control Test (ACT) and GINA Classification including FEV1 in predicting asthma severity. Phil Heart Center J 2007;13(2):149-154. http://www.phc.gov.ph/about-phc/journals/pdf/mendoza.pdf

27. Adams RJ, Fuhlbrigge A, Guilbert T, Lozano P, Martinez F. Inadequate use of asthma medication in the United States: results of the asthma in America national population survey. J Allergy Clin Immunol 2002;110:58-64. http://dx.doi.org/10.1067/mai.2002.125489

28. Vervloet $D$, Williams AE, Lloyd A, Clark TJH. Costs of managing asthma as defined by a derived Asthma Control Test score in seven European countries. Eur Respir Rev 2006;15(98):17-23. http://dx.doi.org/10.1183/09059180.06.00009803

29. Shirai T, Furuhashi K, Suda T, Chida K. Relationship of the asthma control test with pulmonary function and exhaled nitric oxide. Ann Allergy Asthma Immunol 2008;101(6):608-13. http://dx.doi.org/10.1016/\$1081-1206(10)60223-2

30. Horne R, Price D, Cleland J, et al. Can asthma control be improved by understanding the patient's perspective? BMC Pulm Med 2007;7:8. http://dx.doi.org/10.1186/1471-2466-7-8

Available online at http://www.thepcrj.org 
Appendix 1: Sensitivity, specificity, predictive values, likelihood ratios, correctly classified rate and AUC of the ACT in subgroups of patients

\begin{tabular}{|c|c|c|c|c|c|c|c|c|c|c|c|}
\hline & $\mathrm{N}$ & $\%$ & $\begin{array}{l}\text { Cut-off } \\
\text { point }\end{array}$ & Sn & $\mathrm{Sp}$ & $(+) \mathrm{PV}$ & $(-) P V$ & $(+) L R$ & $(-) L R$ & $\begin{array}{l}\text { Correctly } \\
\text { classified }\end{array}$ & AUC \\
\hline \multicolumn{12}{|c|}{ Subgroups of asthma severity } \\
\hline Stage 2 & 82 & 25 & 19 & 78 & 90 & 83 & 86 & 7.8 & 0.2 & 85 & 0.84 \\
\hline Stage 3 & 90 & 28 & 19 & 78 & 90 & 91 & 77 & 7.8 & 0.2 & 83 & 0.87 \\
\hline Stages $1 \& 2$ & 153 & 47 & 19 & 70 & 95 & 88 & 85 & 13.9 & 0.3 & 86 & 0.85 \\
\hline Stages $3 \& 4$ & 170 & 53 & 19 & 70 & 90 & 89 & 72 & 6.9 & 0.3 & 79 & 0.84 \\
\hline \multicolumn{12}{|c|}{ Subgroups of gender } \\
\hline Female & 138 & 43 & 19 & 72 & 92 & 89 & 79 & 8.9 & 0.3 & 83 & 0.86 \\
\hline $12-18$ & 62 & 19 & 19 & 50 & 92 & 81 & 72 & 6.0 & 0.6 & 74 & 0.74 \\
\hline 19-80 & 261 & 81 & 19 & 74 & 93 & 90 & 80 & 10.6 & 0.3 & 85 & 0.87 \\
\hline $12-35$ & 164 & 51 & 19 & 62 & 90 & 82 & 77 & 6.6 & 0.4 & 79 & 0.81 \\
\hline $36-80$ & 159 & 49 & 19 & 78 & 95 & 94 & 82 & 16 & 0.2 & 87 & 0.87 \\
\hline
\end{tabular}


Appendix 2: Agreement and correctly classified rate of GINA and ACT in classifying asthma control in subgroups of patients

\begin{tabular}{|c|c|c|c|c|c|}
\hline & $\mathrm{N}$ & $\%$ & kappa & $p$ value & Correctly classified \\
\hline Stage 1 & 71 & 22 & 0.57 & $<0.001$ & $83 \%$ \\
\hline Stage 2 & 82 & 25 & 0.53 & $<0.001$ & $76 \%$ \\
\hline Stage 3 & 90 & 28 & 0.56 & $<0.001$ & $73 \%$ \\
\hline Stages 3 and 4 & 170 & 53 & 0.53 & $<0.001$ & $71 \%$ \\
\hline \multicolumn{6}{|c|}{ Subgroups of gender } \\
\hline Female & 138 & 43 & 0.56 & $<0.001$ & $75 \%$ \\
\hline $19-80$ & 261 & 81 & 0.58 & $<0.001$ & $76 \%$ \\
\hline $12-35$ & 164 & 51 & 0.46 & $<0.001$ & $73 \%$ \\
\hline $36-80$ & 159 & 49 & 0.61 & $<0.001$ & $77 \%$ \\
\hline
\end{tabular}

